\title{
AMINO-ACID LEVELS IN PLEURAL EXUDATES \\ BY
}

\author{
M. SANDLER \\ From the Brompton Hospital, London
}

(RECEIVED FOR PUBLICATION JULY 19, 1955)

Most pleural exudates are of either tuberculous or neoplastic or post-pneumonic origin. When tubercle bacilli or malignant cells can be demonstrated in the pleural fluid or in the patient's sputum, diagnosis is simple. But if these investigations are negative, the answer must lie in the physician's assessment of clinical and radiological findings, often supported by bronchoscopy or thoracotomy in the equivocal case.

Many attempts have been made to find some characteristic of the exudate itself which may be diagnostic. Reports on the value of estimating glucose levels have been conflicting (Foord, Youngberg, and Wetmore, 1929 ; Gelenger and Wiggers, 1949 ; Calnan, Winfield, Crowley, and Bloom, 1951). Electrophoretic protein patterns (Keller, 1954 ; Münz, 1954), hyaluronic acid (Cutinelli, 1951) and pseudocholinesterase levels (Polimeni and Turitto, 1951), fat content (Leuallen and Carr, 1955), concentrations of non-protein nitrogen, urea, uric acid, creatinine, chloride, calcium, phosphate, potassium (Foord and others, 1929 ; Pérez-Sandoval and Rotellar, 1950) are only a few of the many biochemical estimations described in the literature as having similar values in fluids of differing pathogenesis.

Since paper partition chromatography was first applied to clinical problems by Dent (1946), it has been used on many occasions to assess the amino-acid pattern of various biological fluids in a variety of physiological and pathological conditions.

The present investigation deals with the examination of pleural exudates by this technique. A detailed analysis was carried out to determine whether there was a distinctive amino-acid pattern and concentration, and to detect any variation of that pattern which might exist in exudates of differing aetiology.

\section{MeTHODS}

Specimens of pleural exudate and, in certain cases, of plasma, were obtained from 32 patients, in the following clinical groups :
(A) Primary tuberculous complex Post-primary tuberculosis (including exudates follow-

ing artificial pneumothorax)

(C) Carcinoma of bronchus

Exudates, none of which had a total protein content? of less than $3 \mathrm{~g} . / 100 \mathrm{ml}$., were collected into tubescontaining $1 \mathrm{mg}$. heparin as anticoagulant. Haemor-3 rhagic fluids were rejected. After centrifugation to remove cells, $3 \mathrm{ml}$. of fluid was placed in a cellophane $\mathcal{S}$ bag and dialysed against an equal volume of distilled $\vec{s}$ water at $4^{\circ} \mathrm{C}$. for 16 hours. The protein-free dialysatec was desalted electrolytically (Consden, Gordon, and? Martin, 1947) and $400 \mu \mathrm{l}$. (equivalent to $200 \mu \mathrm{l}$. of the original fluid) was transferred to a silicone-coated watch-glass, and evaporated almost to dryness in a vacuum desiccator over phosphorus pentoxide. The small amount of fluid remaining, and also the residue, $\frac{\circ}{\mathbb{D}}$ which was taken up in two washings with $15 \mu$ l. of $\cong$ distilled water, was spotted on to a $20 \mathrm{~cm}$. square of $\vec{O}$ Whatman No. 1 filter paper and run as a two-dimen- 3 sional chromatogram in the manner described by Dent (1951) on a Datta-Dent-Harris (1950) frame. Phenolwater $(4: 1)$ and collidine-lutidine-water $(1: 1: 1)$ were used as solvents for the two phases, with a trace of ammonia and potassium cyanide in the first tank and of diethylamine in the second. After spraying with $x$ $0.1 \%$ ninhydrin in butanol, the papers were placed in 3 a dark drawer to develop, and read after 24 hours (Dent, 1947, 1948).

It is not possible, when using paper chromatography, to express the concentrations of amino-acids identi-응 fied in $\mathrm{mg}$. per $100 \mathrm{ml}$. An approximately quantitative assessment of the results can be made by gradingo numerically the intensity and, as far as possible, the size of the ninhydrin colour reaction in strengths from $N$ 1 to 10 against an arbitrary colour standard when judged under constant lighting conditions (Walshe, 1953).

\section{RESULTS}

When the chromatograms of pleural exudateso were inspected the general pattern was observed to be similar to that of plasma. On comparing the ${ }^{\text {? }}$ chromatograms of plasma and pleural fluid from nine patients, side by side, however, a lower $\frac{O}{\mathrm{O}}$ amino-acid concentration was apparent in the? exudates. Comparison of patterns by inspection $\stackrel{\mathbb{Q}}{\Omega}$ in the four disease groups did not reveal any gross differences. 


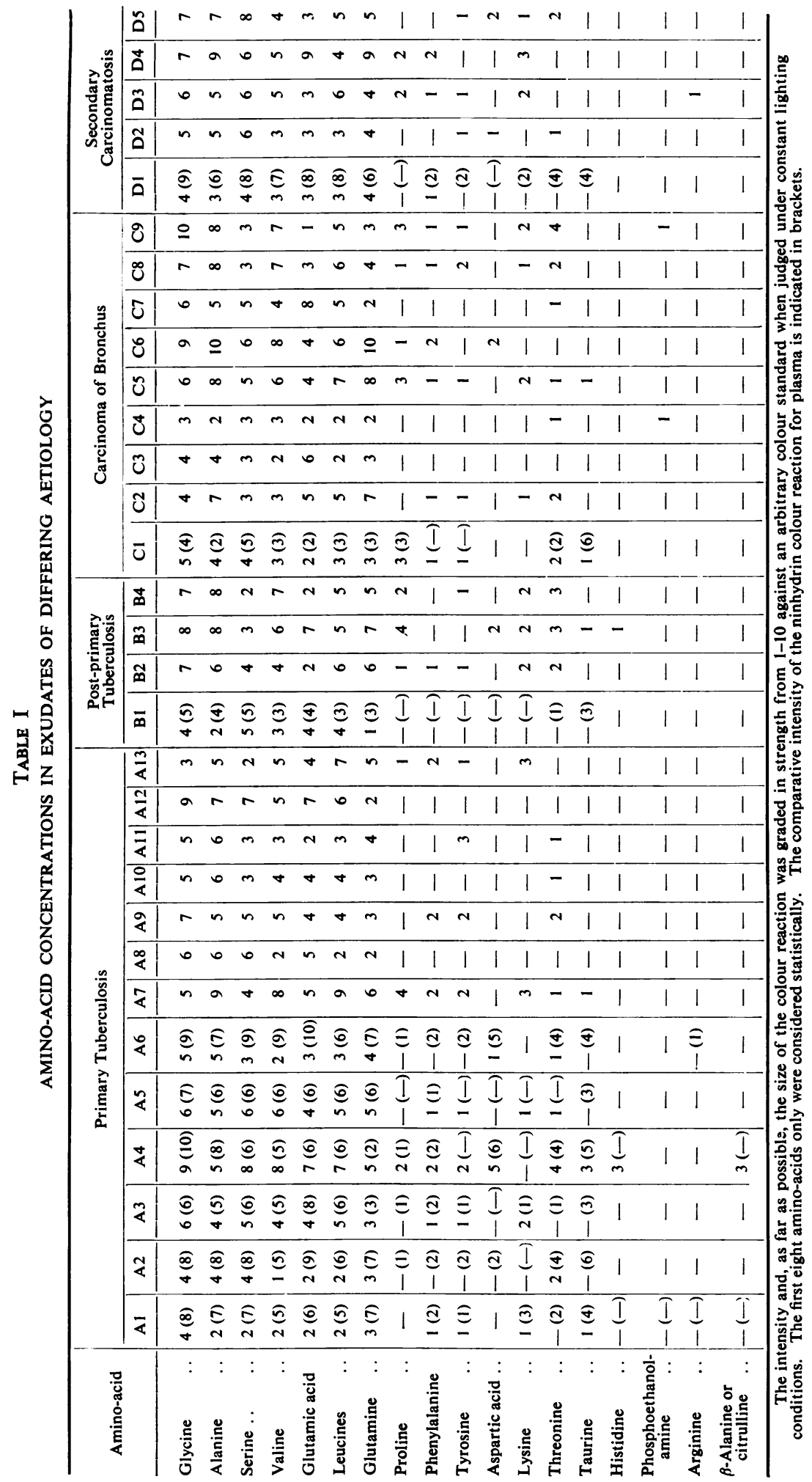

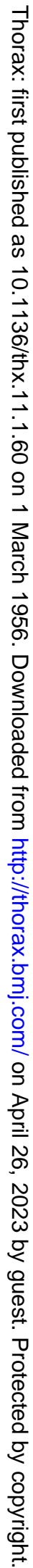


In order to achieve a more precise analysis, concentrations of amino-acids were assessed in arbitrary units as described above, and scores from 1 to 10 were assigned (Table I). These results were then examined statistically.

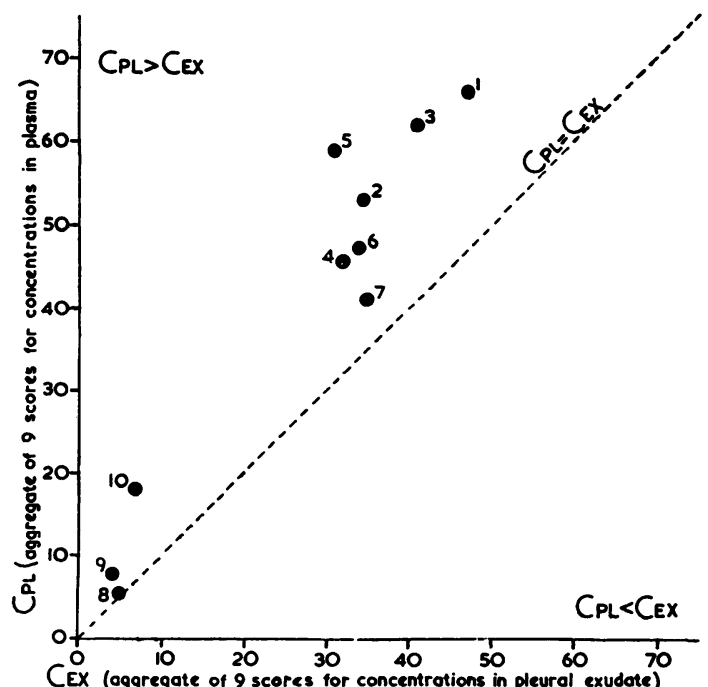

FIG. 1.-Relationship between aggregate scores assigned to concentrations of 10 amino-acids in pleural fluid and in plasma. $1=$ glycine, $2=$ alanine, $3=$ serine, $4=$ valine, $5=$ glutamic acid, $6=$ leucines, $7=$ glutamine, $8=$ proline, $9=$ phenylalanine, $10=$ tyrosine.

For purposes of statistical analysis, values in arbitrary units were replaced by normal scores for ordinal (or ranked) data (Fisher and Yates, 1953). Tests were carried out for the nine patients on whom estimates were made for plasma as well as for pleural fluid, comparing them to determine whether there was a difference between the concentrations of amino-acids in each specimen considered as a group. These tests provided good confirmatory evidence that the general concentration of amino-acids was higher in plasma than in pleural exudate (Fig. 1).

The correlation between the concentrations of various amino-acids in the pleural exudates, independently of disease groups, was also examined. The calculated intercorrelation between eight of the amino-acids is shown in Table II. A purely objective assessment of values in this table suggests that the concentrations of valine and the leucines (leucine and isoleucine appear in the same position on the chromatogram) may vary in a similar manner (Fig. 2). It is also possible that alanine, glutamine, and proline may form a more loosely related group, as may glycine, serine, and glutamic acid.
TABLE II

TOTAL CORRELATIONS (WITHIN DISEASE GROUPS) BETWEEN CONCENTRATION SCORES OE EIGHT AMINOACIDS IN PLEURAL EXUDATE

\begin{tabular}{|c|c|c|c|c|c|c|}
\hline Alanine & Serine & Valine & $\underset{\text { Acid }}{\text { Glutamic }}$ & Leucines & Glutamine & Proline \\
\hline 0.607 & 0.556 & 0.629 & 0.175 & 0.423 & $0 \cdot 148$ & 0.332 \\
\hline \multirow{6}{*}{ Alanine } & $0 \cdot 162$ & 0639 & $0 \cdot 270$ & 0.567 & 0.641 & 0.525 \\
\hline & \multirow[t]{5}{*}{ Serine } & 0.306 & 0.429 & $0 \cdot 303$ & -0.078 & -0.012 \\
\hline & & Valine & 0.242 & 0.831 & 0.345 & 0.589 \\
\hline & & & \multirow{3}{*}{$\underset{\text { acid }}{\text { Glutamic }}$} & $0 \cdot 286$ & 0.092 & 0.062 \\
\hline & & & & \multirow[t]{2}{*}{ Leucines } & 0.352 & 0.545 \\
\hline & & & & & Glutamine & 0.472 \\
\hline
\end{tabular}

In order to detect any differences between the $\vec{z}$ disease groups, simple $\mathrm{F}$ tests were applied to the modified scores of exudate amino-acid concentra- $\stackrel{\rho}{\mathcal{S}}$ tions, considered individually. These did not $\overrightarrow{0}$ demonstrate any variation between the disease of groups.

In view of the correlations between the concentrations of individual amino-acids, it was thought necessary to test for differences between the clinical categories when all the main acids on each chromatogram were considered as a group, using the method of multivariate analysis. Even this

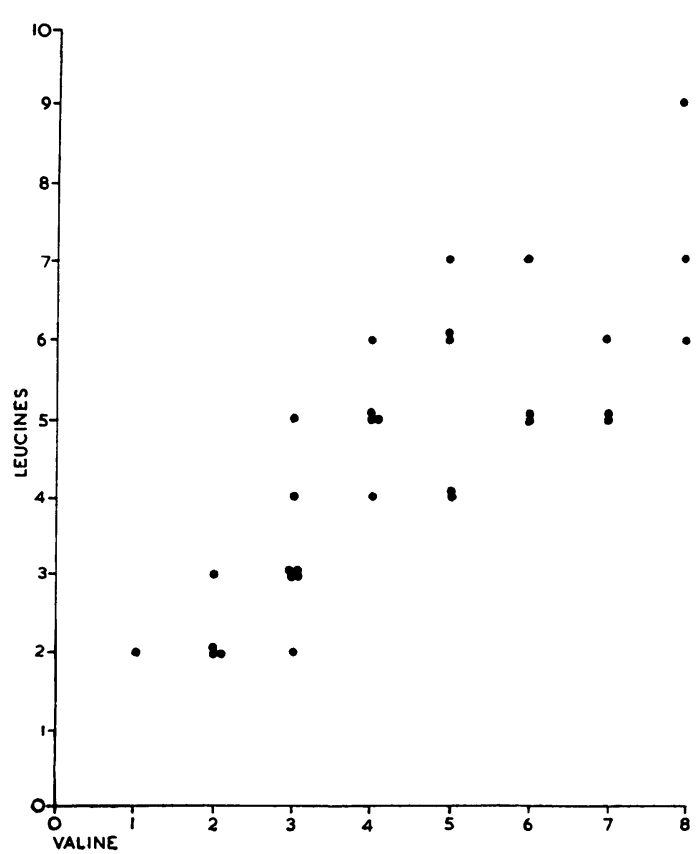

FIG. 2.-Diagram to illustrate correlation between concentration scores of valine and the leucines. 
test, however, demonstrated no significant differences between exudates from patients in the four categories.

\section{Discussion}

Plasma amino-acid levels have been estimated on many previous occasions (Dent, 1947; Agren and Nilsson, 1949 ; Dent and Rose, 1951 ; Walshe, 1953 ; Stein and Moore, 1954), the values found in the present study agreeing substantially with those in the literature.

References to the amino-acid content of pleural fluid are sparse. Apprich and Urban (1937) have determined total amino-acid nitrogen levels in plasma and pleural exudates, finding these to be similar. Their formaldehyde method, however, is not entirely specific for amino-acid $-\mathrm{NH}_{2}$ groups (Hamilton and Van Slyke, 1943). Ellis, Nowinski, and Bieri (1953) have described the chromatographic patterns of exudates from four patients with secondary malignant disease. They did not state the volume of fluid analysed, however, nor did they appear to have desalted their specimens. It is thus felt that their demonstration of the absence of alanine and glutamine may be open to some doubt. Both amino-acids were found in relatively high concentration in all specimens in the present investigation.

The findings in the differential analysis described in this paper, that the concentration of aminoacids, both individual and total, is higher in plasma than in pleural fluid, may at first sight be surprising. For our present concept of the mechanism of formation of pleural exudate suggests that the fluid is derived directly from blood capillaries due to an alteration in their permeability secondary to inflammatory change (Menkin, 1953). One might thus expect small molecule constituents to be present in that exudate in equal concentration to that found in plasma.

It is suggested that this may be true at the outset when the exudation begins, but the subsequent formation of a fibrin barrier, coupled with increased intrathoracic pressure, which may occlude the resorptive capillaries and lymphatics in the boundary tissues, transforms the fluid collection into a relatively static pool.

The occlusion of their capillary blood supply may also partially deprive the exudate boundary tissues of nutriment. It is suggested that these tissues may then derive at least part of their amino-acid requirement from the nutrient fluid they surround. A small number of pleural transudates also examined (insufficient for statistical evaluation) appeared to show a similar decrease in amino-acid content when compared with their analogous plasma. This may be supporting evidence. The lower concentration of glucose in exudate than in plasma, usually found even in non-tuberculous conditions (Calnan and others, 1951), may too be capable of explanation on this basis. It would be necessary to resort to radioisotope experiments to confirm the hypothesis.

Although the correlation between valine and the leucines may perhaps also be explained in terms of tissue requirements, Dent (1955) has also observed a correlation in the rise and fall of these amino-acids in some urines from patients with the Fanconi syndrome. This problem must be left open for the present; but it is of interest that valine, leucine, and isoleucine are closely related chemically.

That there are no gross differences in aminoacid configuration of fluids from the four clinical groups is perhaps not unexpected, if one considers that pleural exudation is probably a nonspecific inflammatory body response to a variety of noxious stimuli.

The diagnostic future may lie in the detection of abnormal metabolites of tubercle bacilli or neoplastic cells, rather than in assaying the normal constituents of a large nutrient pool in an attempt to trace a small change due to abnormal cell requirements of the pathogenic agents.

\section{SUMmary}

The amino-acid pattern of 32 pleural exudates of tuberculous or neoplastic origin was determined by paper partition chromatography.

In nine cases amino-acid concentrations in plasma and exudate were compared. Significantly lower values were obtained for the exudate than for its analogous plasma. To explain this, a hypothesis is presented that amino-acid absorption may take place in exudate boundary tissues.

A high correlation was noted between the rise or fall in concentration of valine and the leucines.

There appears to be no statistically significant difference between the amino-acid configuration of tuberculous or neoplastic exudates.

I should like to thank the physicians of the Brompton Hospital for specimens of fluid from patients under their care. Dr. J. W. Whittick and Dr. P. Forgacs very kindly obtained specimens of fluid also.

My thanks are also due to Dr. S. W. A. Kuper for his encouragement and advice and to Dr. D. N. Baron for his valuable criticism.

This work was done while in receipt of a grant from the Research Fund of the Hospitals for Diseases of the Chest. 


\section{REFERENCES}

Agren, G., and Nilsson, T. (1949). Acta chem. scand., 3, 525. Apprich, K., and Urban, F. F. (1937). Biochem. Z., 292, 360.

Calnan, W. L., Winfield, B. J. O., Crowley, M. F., and Bloom, A. (1951). Brit. med. J., 1, 1239.

Consden, R., Gordon, A. H., and Martin, A. J. P. (1947). Biochem. $J ., 41,590$.

Cutinelli, C. (1951). Riv. Ist. sieroter. ital., 26, 17.

Datta, S. P., Dent, C. E., and Harris, H. (1950). Biochem. J., 46, xlii.

Dent, C. E. (1946). Lancet, 2, 637.

- (1947). Biochem. J., 41, 240.

- (1948). Ibid., 43, 169.

(1951). Recent Advances in Clinical Pathology, ed. S. C Dyke, 2nd ed., p. 238. Churchill, London.

(1955). Personal communication.

-_ and Rose, G. A. (1951). Quart. J. Med., 20, 205.
Ellis, J. P., Nowinski, W. W., and Bieri, J. G. (1953). Tex. Rep. Biol. Med., 11, 231.

Fisher, R. A., and Yates, F. (1953). Statistical Tables for Biological, Agricultural and Medical Research, p. 76, 4th ed. Oliver and Boyd, Edinburgh.

Foord, A. G., Youngberg, G. E., and Wetmore, V. (1929). J. Lab. clin. Med., 14, 417.

Gelenger, S. M., and Wiggers, R. F. (1949). Dis. Chest, 15, 325.

Hamilton, P. B., and Van Slyke, D. D. (1943). J. biol. Chem., 150, 231.

Keller, C. (1954). Dtsch. Arch. klin. Med., 201, 136.

Leuallen, E. C., and Carr, D. T. (1955). New Engl. J. Med., 252, 79. Menkin, V. (1953). Int. Arch. Allergy, 4, 131.

Münz, J. (1954). Čas. Lék. česk., 93, 103.

Pérez-Sandoval, D., and Rotellar, E. (1950). Rev. clin. esp., 36, 41. Polimeni, R., and Turitto, P. (1950). Rass. Fisiopat. clin. ter., 22, 935 Stein, W. H., and Moore, S. (1954). J. biol. Chem., 211, 915.

Walshe, J. M. (1953). Quart. J. Med., 22, 483. 